\title{
PRELIMINARES RELACIONAIS ENTRE A VALIDADE DA ORIGEM E A ORIGEM DA VALIDADE
}

\author{
Relaciones preliminares entre la validez de origen y el origen de validez
}

Sandro Adams ${ }^{1}$

\begin{abstract}
RESUMO: Este diagnóstico teórico parte de um fardo latino-americano: a fé na ciência é um pilar da modernidade. Para isso, pondera algumas categorias analíticas de uma teoria sociológica que transita entre a busca da universalidade comunicativa (Habermas) e a crítica da intersubjetividade do sujeito (Foucault). Por paradoxal que possa vir a sugerir, retém na crítica da modernidade a defesa do projeto ocidental. É por isso, e nada mais, que se atem as racionalidades (episteme?) forjadas por estes filósofos-sociólogos ou sociólogos-filósofos (a indecisão precede o substantivoadjetivo e, a nosso ver, é coerente manter se indeciso sem, no entanto, o ser contraditório). Ora, se Habermas postula o nascimento da racionalidade instrumental na modernidade, isto não o será tão claramente posto por Foucault. No fundamento, Habermas destaca basicamente três categorias analíticas: mundo da vida, racionalidade comunicativa e ação estratégica (ou sistêmica). Seu leimotiv é a construção de uma ética do discurso. Por questões didáticas, centrar-se-á na linguagem (e não na axiologia). Já a trajetória de Foucault é dividida em três períodos: a) a articulação dos saberes na Arqueologia; b) os dispositivos do poder na Genealogia; c) a conduta individual da Ética. Porém, e ante a teoria foucaultiana, seria possível discutir o tema do poder isolado do saber ou apartado da relação ética entre ambos e a partir de uma desrazão? Neste sentido, seu pano de fundo é a superação da problemática da subjetividade.
\end{abstract}

Palavras-chaves: Ciência. Razão. Saber.

RESUMEN: Éste diagnóstico teórico es basado en una carga latinoamericana: la fe en la ciencia es un pilar de la modernidad. Para ello, considera algunas categorías analíticas de una teoría sociológica que transita entre la búsqueda de la universalidad comunicativa (Habermas) y la crítica de la intersubjetividad del sujeto (Foucault). Por paradójico que pueda sugerir, conserva la defensa del proyecto occidental en la crítica de la modernidad. Es por eso, y nada más, que se adjuntan las racionalidades (¿episteme?) forjadas por estos filósofos-sociólogos o sociólogos-filósofos (la indecisión precede al sustantivo-adjetivo y, a nuestro juicio, es coherente permanecer indeciso sin, sin embargo, el ser contradictorio). Ahora bien, si Habermas postula el nacimiento de la racionalidad instrumental en la modernidad, Foucault no lo declarará tan claramente. Esencialmente, Habermas destaca básicamente tres categorías analíticas: mundo de la vida, racionalidad comunicativa y acción estratégica (o sistémica). Su leitmotiv es la construcción de una ética del discurso. Por razones didácticas, se centrará en el lenguaje (y no en la axiología). La trayectoria de Foucault se divide en tres períodos: a) la articulación del conocimiento en Arqueología; b) los dispositivos de poder en la genealogía; c) la conducta individual de la Ética. Sin embargo, y a la vista de la teoría de Foucault, ¿`sería posible discutir la cuestión del poder aislado

\footnotetext{
${ }^{1}$ Mestrando em sociologia no Programa de Pós-Graduação em Sociologia da Universidade Federal de Pelotas - Bolsista da Coordenadoria de Aperfeiçoamento Pessoal de Nível Superior/CAPES. Email: sandroadams@gmail.com
} 
del conocimiento o al margen de la relación ética entre ambos y de una sinrazón? En este sentido, su trasfondo es superar el tema de la subjetividad.

Palabras-clave: Ciencia. Razón. Saber.

\section{INTRODUÇÃO}

Este diagnóstico teórico parte de um fardo latino-americano: a fé na ciência é um pilar da modernidade. Para isso, pondera algumas categorias analíticas de uma teoria sociológica que transita entre a busca da universalidade comunicativa (Habermas) e a crítica da intersubjetividade do sujeito (Foucault). Por paradoxal que possa vir a sugerir, retém na crítica da modernidade a defesa do projeto ocidental. É por isso, e nada mais, que se atem as racionalidades (episteme?) forjadas por estes filósofossociólogos ou sociólogos-filósofos (a indecisão precede o substantivo-adjetivo e, a nosso ver, é coerente manter se indeciso sem, no entanto, o ser contraditório).

Ora, se Habermas postula o nascimento da racionalidade instrumental na modernidade, isto não o será tão claramente posto por Foucault. No fundamento, Habermas destaca basicamente três categorias analíticas: mundo da vida, racionalidade comunicativa e ação estratégica (ou sistêmica). Seu leimotiv é a construção de uma ética do discurso. Por questões didáticas, centrar-se-á na linguagem (e não na axiologia). Já a trajetória de Foucault é dividida em três períodos: a) a articulação dos saberes na Arqueologia; b) os dispositivos do poder na Genealogia; c) a conduta individual da Ética. Porém, e ante a teoria foucaultiana, seria possível discutir o tema do poder isolado do saber ou apartado da relação ética entre ambos e a partir de uma desrazão? Neste sentido, seu pano de fundo é a superação da problemática da subjetividade.

\section{A VALIDADE DA ORIGEM E A ORIGEM DA VALIDADE}

1. A ciência, depois de Kant, não foi pensada filosoficamente. Isto possibilitou que o positivismo pudesse "esquecer o entrelaçamento da metodologia das ciências com o processo objetivo de formação da espécie humana, erigindo o absolutismo da metodologia pura sobre os escombros do esquecido e do reprimido" (HABERMAS, 1982, p. 27). A validade do conhecer passou a ser definida 
pelo sucesso da ciência tecnocrática e sua capacidade descritiva da realidade. Esta racionalidade instrumental é o momento antropocêntrico de imposição subjetiva no mundo objetivo que tem como característica fundamental a dominação da natureza. É possível admitir, inclusive, que o objetivo do saber de caráter tecnológico é um interesse técnico da manipulação do humano tratado como nãohumano (Cf. HABERMAS, 2002a). Ante isto, Habermas defende uma reflexão crítica em que a "teoria penetra na práxis da existência através da adequação do espírito ao movimento cósmico: ela imprime sua forma à existência, disciplinando-a no seu éthos" (HABERMAS, 1975, p. 291). O problema é que a ciência não está prestando contas à práxis na medida em que a teoria não está sendo orientada pela emancipação do ser humano. Assim, a racionalidade moderna é instrumental, isto é, um esclarecimento sem esperança.

Por outro lado, toda a tradição filosófica poderia ser resumida, até Hegel, da seguinte forma: ou se dá primazia ao objetivo em detrimento do subjetivo; ou se dá primazia ao subjetivo em detrimento do objetivo. É justamente Hegel quem eleva a modernidade a tema filosófico ao formular uma racionalidade objetiva que perpassa a intersubjetiva num doloroso intento de apreender o tempo no conceito. Neste sentido, a auto-reflexão busca sua fundamentação a partir de si própria e sem apelar para a tradição, os costumes, ou algo acumulado historicamente como verdadeiro. A modernidade é fruto de sua própria racionalidade e precisa "extrair de si mesma a sua normatividade" (HABERMAS, 2000, p. 12).

Habermas reconhece que esta normatividade epistemológica é produzida por sujeitos teóricos que se movem em busca do conhecimento orientado por um desejo. É importante destacar que Habermas sempre concilia racionalidade (razão) e ação (agir) porque para cada racionalidade há um tipo específico de interesse que culmina em um tipo específico de conhecimento: (a) conhecimento técnico: interesse técnico instrumental que regula as ciências empírico-analíticas; (b) conbecimento prático: interesse instrumental comunicativo das ciências humanas em que prevalece o espaço da inter-comunicação humana na esfera prática; (c) conhecimento emancipatório: interesse das ciências emancipatórias como uma espécie de síntese adequada entre ação e ciência na busca da emancipação do ser humano a partir de si próprio e em relação com os demais.

Ante isto, Habermas aponta para a dimensão da "distorção sistemática da comunicação pelos efeitos dissimulados da violência" (RICOEUR, 1983, p. 119): (a) Distorção ideológica da linguagem: os fenômenos de dominação de uma determinada classe econômica sobre outra são resultados do trabalho humano. É preciso identificar e tratar da relação entre trabalho, poder e linguagem para demonstrar que o "fenômeno da dominação produz-se na esfera da ação comunicativa" (RICOEUR, 1983, p. 125); (b) Distorşão compreensiva: posto que a distorção da linguagem em sistema ideológico nasce da relação entre trabalho e poder, fica saliente que não existe não-compreensão, mas uma compreensão 
sistematicamente distorcida; (c) Dissolução das ideologias pelo viés explicativo: para criticar a ideologia e a distorção comunicativa da linguagem, é preciso explicar e não somente compreender.

É importante destacar que a distorção comunicativa ocorre quando dois sujeitos falam, mas um consente com o outro pela autoridade (epistêmica, legislativa, judiciária), por medo, por não ter o que dizer, por não entender o que o outro diz: é a invasão sistêmica da ciência, com sua linguagem científica, ao mundo da vida e que justifica a opressão em nome de uma possível emancipação ilustrada. Esta consideração empírica reforça um elo dissuadido entre Foucault e Habermas. Para Habermas, o problema central está na validade do enunciado comunicativo (instrumental ou emancipatório). É aqui que a distorção assume o papel da legitimidade. Neste pressuposto, a crítica habermasiana a Adorno é feroz (e não mamão com açúcar, como alguns podem sugerir) ${ }^{2}$. Por outro lado, Foucault se atenta ao nascimento e a imposição da ciência como o único saber legítimo e verdadeiro do Ocidente. É por esse caminho construído a partir da teoria foucaultiana que se é possível iniciar o reconhecimento das atrocidades cometidas aos indígenas justificadas por uma ciência, que no dizer de Habermas, não era instrumental. Antecipando: há uma desrazão que pertence também ao mundo da vida. Habermas tentará esquivar-se deste problema de uma forma contundente ${ }^{3}$. E por quê?

Porque Habermas amplia o projeto moderno de razão e aposta numa filosofia/sociologia crítica baseada no processo emancipatório da inter-comunicação humana. Numa palavra, a razão é dialógica e não monológica. Para sustentar e "salvar" o aspecto emancipatório da razão, postula a passagem da razão para as racionalidades (da teoria das ideologias para a teoria das racionalidades). A teoria da racionalidade é a ampliação da crítica da ideologia na co-implicação entre a filosofia (teoria da racionalidade) e o social (fazer diagnósticos das patologias da sociedade vigente - teoria crítica da modernidade). É esta teoria que fornece os padrões críticos da teoria da sociedade em que se conduz a tradicional razão para fora do gueto da pura imanência conceitual, isto é, a racionalidade não é somente formalidade gramatical, mas procedimento argumentativo em busca de entendimento. Posto isto, alfineta um diagnóstico: tanto a filosofia adorniana (crítica da sociedade) quanto a sociologia foucaultiana (desmancha a abstração conceitual) estão equivocadas porque saciam-se de uma crise neutra (Cf. FREITAG, 1994, p. 52-65).

2. Por ora, uma dúvida se impõe e cria duas rotas distintas a serem seguidas: (a) é imprescindível situar o debate entre Habermas e Foucault? Não; (b) É necessário? Sim. E o que se fará? Nem um e nem o outro. Não tentara, ao menos neste momento, se espremer entre ambos, mas, antes, transitar sobre uma linha imaginaria como uma lesma. Vagarosamente Foucault. Vagarosamente

\footnotetext{
2 Para um panorama interessante e, no mínimo, tenso: HABERMAS; HENRICH; TAUBES (orgs). Hermeneutik und Ideologiekritik. Mit Beiträgen von Karl-Otto Apel, Claus v. Bormann, Rüdiger Bubner, Hans-Georg Gadamer, Hans Joachim Giegel, Jürgen Habermas. Frankfurt: Suhrkamp, 1971. ${ }^{3}$ Para uma crítica a Habermas: APEL; DUSSEL. Ética del discurso y ética de la liberación. Madri: Trotta, 2004.
} 
Habermas. Não se terminará o percurso e, possivelmente o único mérito deste texto, buscará visualizar o trajeto inicial (e amplo) da gosma grudenta.

Neste sentido, concordar-se-á que tanto Habermas quanto Foucault são críticos das "caixas de gaveta" do armário colossal da ciência. E, por exemplo, este mestrando preferiria usar a gravata de Habermas para demonstrar como Luhmann emprega sua teoria para legitimar o poder. Contudo, isto criaria um impasse metodológico: é necessário, primeiramente, negar toda uma tradição de cientistas brasileiros que situam Habermas como reformador da teoria de Weber, Mead, Durkheim, Parsons e da escola frankfurtiana (até Piaget - enquanto processo de aprendizagem moral da humanidade). Por isso, esse reorientar da produção crítica habermasiana no confronto direto e dileto com uma tradição sociológica e filosófica alemã é incômoda. Talvez Foucault, olhando para além da proposta de Freitag (1994) que se repete em dezenas de artigos/livros e saindo do discurso filosófico da modernidade, possa corroborar a disputa pelo modus operandi moderno do fazer-se ciência.

Foucault concorda que a ciência, após Kant, não tratou o projeto de esclarecimento como uma atividade estritamente moderna. E ratifica que Hegel é aquele que robustece a modernidade a um padrão normativo ocidental. Entretanto, parte de uma questão norteadora diferente da proposta habermasiana, porém similar: quais são as condições da formação de diferentes saberes, conhecimentos, racionalidades numa determinada sociedade ou cultura? Esta pergunta manifesta sua insatisfação metodológica com relação ao saber descritivo/objetivo das ciências positivistas. Assim, a cientificidade não serve como critério de análise para compreender a formação e a transformação dos conhecimentos porque não indaga em "qual espaço de ordem se constituiu o saber" (FOUCAULT, 2002a, p. XVIII). Se Habermas retomou o conceito de racionalidade nas ciências modernas, Foucault irá recorrer a um conceito grego-moderno: a episteme enquanto "campo epistemológico" (FOUCAULT, 2002a, p. XIX). Ambos produziram um "significado novo para um nome velho" (TERNES, 2000, p. 56).

Episteme é a noção que estabelece uma análise comparativa de épocas distintas para identificar a descontinuidade/ruptura entre os saberes. Assim, por exemplo, as ciências humanas não seriam parte do progresso da humanidade rumo ao desvelamento do ser do homem. Simplesmente ocupam um espaço tornado possível pela episteme moderna que abriu a possibilidade de inventar o homem. Por isso, tenderiam a desaparecer quando desaparecesse o homem. Isso significa que cada época possui uma única episteme que "define as condições de possibilidade de todo saber" (FOUCAULT, 2002a, p. 230). É a partir dela que se formam os saberes específicos cuja diferença se dá na superfície. $\mathrm{Na}$ sua radicalidade original, irá concluir que o marxismo não é uma descontinuidade porque “está para o pensamento do século XIX como peixe n’água: o que quer dizer que noutra parte qualquer deixaria de respirar" (FOUCAULT, 2002a, p. 360). O "marxismo acadêmico" europeu consiste no fato de que as "condições econômicas, sociais e políticas da existência não fazem mais do 
que depositar-se ou imprimir-se neste sujeito definitivamente dado" (FOUCAULT, 2002c, p. 8). Aqui, cabe enfatizar, Habermas concorda que a invasão sistêmica do marxismo acadêmico ao mundo da vida inebria uma abstração que retém o domínio da práxis.

Em nova dobra reflexiva, Foucault indaga: onde se encontra o subsolo que serve de suporte invisível do visível? Concluirá que o saber não está nas instituições sociais, mas no "discurso, sua autonomia e suas transformações descontínuas" (RABINOW; DREYFUS, 1995, p. 19). Dito de outro modo, não há ciência sem saber, mas o "saber, enquanto saber, tem uma existência independente de sua possível transformação em saber científico (MACHADO, 1982, p. 84). Ora, se a ciência depende do saber para ser ciência, por que utilizar o critério científico que insiste em encontrar uma ordem interna ou uma estrutura metafisica velada? Foucault trata a episteme enquanto o "conjunto das relações que podem unir, em uma dada época, as práticas discursivas que dão lugar a figuras epistemológicas, a ciências, eventualmente a sistemas formalizados" (FOUCAULT, 2005a, p. 214). Fica evidente que Foucault se indaga sob as condições de existência dos saberes e não sua validade. Aqui, sua preocupação é com a regularidade dos saberes, suas condições de existência e compatibilidades e incompatibilidades.

3. Entretanto, e por outra perspectiva, Habermas expõe fissuras e sustenta que há uma crise no projeto ocidental de ciência. Esta crise da humanidade europeia é o "fracasso aparente do racionalismo" (HUSSERL, 2002, p. 96) que aponta para a crise do projeto moderno antropológico, axiológico e existencial. Habermas sustenta esta tese em três posições:

a) O termo pós-moderno expressa a "incredulidade perante o metadiscurso filosóficometafísico" (BARBOSA, 1988, p. VII) e a descrença nas pretensões científicas atemporais e universalizantes. Habermas é, ao mesmo tempo, o filósofo/sociólogo da multiplicidade das vozes (pósmoderno) e o defensor de um conceito mais amplo e abrangente da razão (moderno). A crise das metanarrativas é complementada pela patologia do distúrbio comunicativo, isto é, quando se troca uma metanarrativa por outra metanarrativa ideológica que não se quer metanarrativa. Dito de outro modo, Habermas é um moderno criticando a pós-modernidade pela modernidade e para defender o arcabouço do esclarecimento. Já Foucault é um pós-moderno criticando a modernidade pela pósmodernidade e que defende uma atitude de pensar e agir que se apresenta como tarefa do Aufklärung kantiano. Entretanto, e curiosamente, Habermas não aceita que Foucault faça uso deste mesmo estado de espirito.

b) O mundo da vida é o espaço cultural da comunicação. Este espaço da ação comunicativa é caracterizado pelas experiências subjetivas e intersubjetivas num horizonte que visa o entendimento: é o lugar do saber comum. É o lugar/local transcendental em que ocorre a razão comunicativa. É aqui que a linguagem tem sentido e possibilita o dissenso sobre um consenso. Assim, o consenso empírico nos remete a afirmar que consenso algum é definitivo porque a identidade social do mundo da vida 
pode ser sempre posta em questão. É neste espaço que acontece a reprodução cultural (cultura), integração social (sociedade) e socialização individual (personalidade).

c) Por fim, a razão sistêmica é a razão instrumental em que domina a razão calculista: neste espaço impera a ação estratégica instrumental voltada a economia/poder e a linguagem é um meio usado parcialmente e destinado a conquista de interesses particulares. O problema é que o mundo da vida está sendo colonizado pela razão instrumental na medida em que as relações humanas de comunicação são substituídas por relações calculistas sem espaços para trocas intersubjetivas isentas de interesses puramente mercantis.

Por outra via, e mais próxima ao que aqui se pode tratar, Foucault irá transitar da invenção moderna para as práticas sociais. É aqui que Foucault rompe com o academicismo e proclama que se "quisermos realmente conhecer o conhecimento, saber o que ele é, apreendê-lo em sua raiz, em sua fabricação, devemos nos aproximar, não dos filósofos, mas dos políticos, devemos compreender quais são as relações de luta e de poder" (FOUCAULT, 2002c, p. 23). No dizer de Habermas, dialeticamente viver o mundo da vida e retirar a validade exclusiva da razão instrumental.

É na emergência deste contexto da relação dos elementos externos na formação e funcionamento dos saberes que Foucault introduz a categoria do poder. Como os saberes locais e específicos foram dominados por discursos científicos que trazem em si a característica de serem saberes neutros? Novamente, os saberes são postos em questão não a partir de critérios científicos, mas a partir da análise dos saberes que historicamente não foram considerados para "ativar saberes locais, descontínuos, desqualificados, não legitimados, contra a instância teórica unitária que pretendia depurálos, hierarquizá-los, ordená-los em nome de um conhecimento verdadeiro, em nome dos direitos de uma ciência detida por alguns" (FOUCAULT, 2004a, p. 171).

Esta ferramenta metodológica lhe permite situar como os saberes foram constituídos e influenciados historicamente. Entender o saber como construção histórica implica uma crítica radical: o limite da filosofia ocidental está em postular um sujeito humano fixo e permanente a partir do qual o conhecimento seria possível. O sujeito "se constitui no interior mesmo da história, e que é cada instante fundado e refundado pela história" (FOUCAULT, 2002c, p. 10).

4. Esta fixação metafisica do sujeito obedece a uma razão monológica. Por isso, a proposta habermasiana sustenta o agir comunicativo como a interação intersubjetiva dialógica em que sujeitos são situados diante de outros sujeitos a fim de que se entendam sobre algo. Acontece no mundo da vida e é "responsável pela absorção dos riscos e pela proteção da retaguarda de um consenso de fundo" (HABERMAS, 2002b, p. 86) em que o "sujeito monológico é substituído pelo 'grupo" (PIZZI, 1994, p. 108). Neste caso, a linguagem é o ponto central da ação comunicativa e da intersubjetividade como instância obrigatória para o conhecimento e para a ação. 
A especificidade da razão comunicativa é ser, ao mesmo tempo, imanente e transcendente. É só encontrável em contextos concretos dos jogos de linguagem e instituições de vida humana, mas, por outro lado, é igualmente uma "ideia regulativa", na qual nos orientamos, quando criticamos nossa vida histórica. Neste sentido, a linguagem assume a dimensão central da epistemologia na racionalidade comunicativa, sendo o médium entre sujeitos que agem comunicativamente.

Esta passagem do paradigma da consciência para a comunicação/linguagem tomou forma de um fundamento primário no ato de conhecer do humano. Aqui, não se pode prescindir de um fator pragmático inevitável, a epistemologia: todo conhecer a partir da linguagem assenta-se na comunicação pública feita numa comunidade, isto é, é a proposta de superação da filosofia solipsista da consciência em que a "guinada lingüística colocou o filosofar sobre uma base metódica mais segura e o libertou das aporias das teorias da consciência" (HABERMAS, 2002b, p. 16).

Este modo transcendental de entender a linguagem será complementado pela guinada pragmática em que a linguagem é entendida como uma prática social concreta. A pragmática universal é a reconstrução das condições universais de entendimento que tem como "tarefa apontar as condições de possibilidade do entendimento humano" (MÜHL, 2003, p. 172). As condições de validade de uma fala são as condições de sua universalidade vista pela particularidade e sustentadas pela força do melhor argumento na busca do consenso em que a linguagem tem uma pretensão de compreensibilidade, de aceitabilidade e de validade. A pretensão de validade comporta ainda a pretensão de verdade (discurso teórico), de veracidade (discurso prático) e de retidão moral. É por isso que a linguagem é a produção de conhecimento calcada na intersubjetividade comunicativa.

Habermas ainda faz uma ressalva significativa ao analisar a confrontação entre o método (Dilthey) e a verdade (Heidegger) ${ }^{4}$. Ao opor ciências do espírito e ciências da natureza se cria um dualismo epistemológico que exclui das ciências da natureza a responsabilidade ética pelo humano: parece que o importante, para ambos, é afirmar que as ciências do espírito não têm um método porque tratam do acontecer humano, enquanto que as ciências da natureza têm um método próprio de pesquisa e de busca da verdade.

Foucault irá regredir ainda mais na tradição ocidental: é com o nascimento e consolidação da filosofia como saber por excelência que o verdadeiro saber não será mais o saber empírico (político), mas um saber essencial que só o filósofo (ou a ciência moderna) poderá alcançar. Restou ao Ocidente uma concepção de que o poder é algo feio, perigoso, sujo. Já o saber foi concebido como algo limpo, puro, anti-estratégico. Impregnou-se na cultura ocidental um mote de que o saber se constitui a partir de mentes enclausuradas, tranquilas e serenas que não sofrem as influências de suas culturas e épocas

\footnotetext{
${ }^{4}$ Sua inquietude é, em 1953, deveras interessante: "parece chegada a hora em que devemos pensar com Heidegger contra Heidegger" (HABERMAS, 1984, p. 72).
} 
específicas. A instauração deste mito platônico se efetivou na história baseado na "antinomia entre saber e poder. Se há saber, é preciso que ele renuncie ao poder. Onde se encontra saber e ciência em sua verdade pura, não pode mais haver poder político” (FOUCAULT, 2002c, p. 51). Essa separação provocada no início da filosofia gradativamente foi se afirmando, de modo que "somente aqueles que estão à distância do poder, que não estão em nada ligados à tirania, fechados em suas estufas, em seus quartos, em suas meditações, podem descobrir a verdade" (FOUCAULT, 2004a, p. 141).

5. Habermas, em sua preocupação com a validade epistemológica, compreendera que, assim como a ciência, a "linguagem também é médium de dominação e de poder social. Ela serve à legitimação de relações de violência organizada" (HABERMAS, 1987, p. 21). Habermas enfatiza: a relação entre linguagem e práxis acontece no mundo da vida dominado por patologias capitalistas (contexto de dominação, opressão e violência). Este é, sem resquício dubio, o legado habermasiano: como fazer uma sociologia militante se este diagnóstico teórico convergir efetivamente na complexidade do real? Se a linguagem esta sistematicamente distorcida, o diálogo também está. É preciso identificar, portanto, quando a linguagem faz o discurso da racionalidade e quando faz o discurso da realidade e, além disso, quando a linguagem diz o sentido compreensível, mas inexplicável?

Este é um problema: como a verdade pode ser fruto de um procedimento formal? Antevêse, no método, um conceito limitado de razão: a razão como, e somente como, capacidade de manipular corretamente regras formais. Para isso, Habermas defende a racionalidade como um procedimento argumentativo questionador da validade que se quer inabalável: a verdade resulta de um diálogo entre pares seguindo a lógica do melhor argumento. Neste sentido, a teoria do consenso da verdade prima pelas afirmações verdadeiras (essência e aparência), afirmações verazes (ser e ilusão) e afirmações corretas (ser e dever) em que a razão comunicativa é a ponte de intersecção entre o mundo objetivo das coisas, o mundo social das normas e o mundo subjetivo dos afetos. O "exercício da racionalidade põe fronteiras à Razão e lhe mostra que há um vasto domínio do mundo - certamente o maior - que é marcado pela irracionalidade" (BARROS, 1993, p. 16).

Foucault compartilha da crítica à uma concepção ingênua de saber (neutra/isenta das relações de poder) e que produziu uma concepção ingênua de verdade (absoluta, universal e definitiva) desvelada pela essência. Porem, se Habermas demonstra que são duas verdades que pertencem a duas sociedades diferentes, Foucault vai além: rechaça de forma radical essa concepção e procura mostrar como a verdade fora produzida na história a partir de múltiplas práticas sociais e como as sociedades, de forma especial a sociedade ocidental, necessitou dela para funcionar.

As sociedades ocidentais se estruturaram a partir da verdade. Foucault recusa a existência de verdades metafísicas e a existência do sujeito como realidade fixa na produção das verdades. Por isso, considera as práticas sociais ou as relações de poder como produtoras da verdade. A "verdade é deste 
mundo; ela é produzida nele graças a múltiplas coerções e nele produz efeitos regulamentados de poder" (FOUCAULT, 2004a, p. 12); é condição de possibilidade em que "somos submetidos pelo poder à produção da verdade e só podemos exercer o poder mediante a produção da verdade" (FOUCAULT, 2002b, p. 28-29); cumpre uma tarefa calculada e precisa. O discurso verdadeiro se estrutura a partir das práticas sociais e tem seu curso dirigido por relações de força, isto é, em "toda sociedade a produção do discurso é ao mesmo tempo controlada, selecionada, organizada e redistribuída" (FOUCAULT, 2005b, p. 8-9). No fundamento, o discurso, o pressuposto, o enunciado, a episteme, o a priori histórico e a prática discursiva "é o que agente faz realmente, em oposição ao que uma ilusão perpetua de generalidade e de racionalidade faz crer que faz" (VEYNE, 2004, p. 34) em que "os pensamentos, os conhecimentos, as palavras, escritas ou práticas de um grupo humano se enquadram dentro de estreitos limites" (VEYNE, 2004, p. 25).

Ora, fica claro que o poder necessita do discurso verdadeiro. Os partícipes da sociedade devem seguir o discurso com suas verdades permitidas e o ritual de dizê-las. O controle é tão permanente e efetivo que se pode dizer apenas parte do discurso. Neste sentido, a verdade é um meio possuidor de regras que funciona como controle social dos discursos: é o "conjunto das regras segundo as quais se distingue o verdadeiro do falso e se atribui ao verdadeiro efeitos específicos de poder" (FOUCAULT, 2004a, p. 13). É o mecanismo da verdade (ciência como controle) que permite ser dito somente o discurso verdadeiro/autorizado. Insiste Foucault: o discurso falso, assim como o discurso da verdade, tem um caráter histórico e não dialógico (como sustenta Habermas).

Por outro lado, cada sociedade possui um ritual próprio (regime de verdade) para fabricar e regular a verdade. Neste sentido, por que o "império da ciência" continua a garantir a crença na verdade científica? Este mito produzido de que todo saber deve ser científico para ser legitimo ainda reverbera nas entranhas da sociedade ocidental. O problema é esta crença ingênua de que a ciência é o único saber imune às coerções externas das relações de poder. Ora, a ciência é uma forma de produzir que foi construída e legitimada historicamente. Foi através dela, de suas regras, que se exerceu o controle do saber a partir da modernidade. No fundamento, a ciência é uma produção histórica.

A ciência é a disciplina global de todas as disciplinas específicas a que foram transformadas o saber. Aqui, a ciência passa a realizar o "policiamento disciplinar dos saberes" (FOUCAULT, 2002b, p. 218). Ocorre uma espécie de cientificização da verdade em que, salvo o momento peculiar norteamericano a insuflar rebeldias de políticos brasileiros expressivos, a verdade científica ainda é vista como verdade absoluta e inquestionável. Ora, "somos forçados a produzir a verdade pelo poder que exige essa verdade e que necessita dela para funcionar" (FOUCAULT, 2002b, p. 29), isto é, o poder "institucionaliza a busca da verdade" (FOUCAULT, 2002b, p. 29). Enfaticamente: nascemos, vivemos e morremos sob os efeitos da verdade. 


\section{CONSIDERAÇÕES FINAIS}

6. Em suma, a teoria habermasiana orienta um "novo" programa metodológico de investigação nas ciências sociais ao sustentar uma racionalidade comunicativa ancorada em uma sociedade que integra dois paradigmas: o sistêmico e o mundo da vida (Cf. HOYOS; VARGAS, 1997). Isto lhe permite elaborar uma crítica defensiva da modernidade que transita da filosofia para a teoria social retirando a necessidade da primazia aristotélico-hegeliana: ou do sujeito, ou do objeto, ou da síntese sujeito-objeto. É sob este alicerce teórico-epistemológico e emancipatório que o conceito de comunicação distingue a sociedade de outras entidades (Cf. BRUNKHORST, 2005, p. 198). No fundamento, uma crítica epistemológica radical somente é possível enquanto uma crítica social dos nexos comunicativos. Já Foucault elaborou no período arqueológico uma noção de verdade histórica determinada pelas próprias regras internas dos saberes nas diferentes épocas. E no segundo período, a noção de verdade preserva seu estatuto de construção histórica, mas é determinada pela exterioridade do próprio saber (relações de poder).

Entre ambos, por enquanto, este mestrando fica com Habermas. No fundamento, há de se propor um novo modo de ler as ilusões ou os problemas da situação contemporânea, "caso contrário, eu deveria escolher um outro gênero literário, talvez o do diário de um escritor helenista, preocupado apenas em documentar para a posteridade as promessas não cumpridas de sua cultura decadente" (HABERMAS, 1997, p. 14).

\section{REFERÊNCIAS BIBLIOGRÁFICAS}

ALVES, Elder Patrick Maia. Norbert Elias. In: TELLES, Sarah (Org.). Clássicos das ciências sociais: os sociólogos. Petrópolis: Vozes, 2018.

BARBOSA, Wilmar do Valle. Tempos pós-modernos. In: LYOTARD, Jena-François. O pósmoderno. Trad. Ricardo Correia Barbosa. Rio de Janeiro: José Olympo, 1988.

BARROS, Roque Spencer Maciel de. Razão e Racionalidade. São Paulo: UPE, 1993.

BRUNKHORST, Hauke. Jürgen Habermas. Die rächende Gewalt der kommunikativen Vernunft. In: HENNIGFELD, Jochem; Jansohn, Heinz (Org.). Philosophen der Gegenwart. Eine Einführung. Darmstadt: Wissenschaftliche Buchgesellschaft, 2005.

FREITAG, Bárbara. A teoria crítica: ontem e hoje. São Paulo: Brasiliense, 1994. 
FOUCAULT, Michel. As palavras e as coisas. Trad. Salma Tannus Muchail. São Paulo: Martins Fontes, 2002a.

. Em defesa da sociedade: Curso no Collège de France (1975-1976). Trad. Maria Ermantina Galvão). São Paulo: Martins Fontes, 2002b.

. A verdade e as formas jurídicas. Trad. Roberto Cabral de Melo Machado e Eduardo Jardim. Rio de Janeiro: NAU, 2002c.

. Microfísica do poder. Rio de Janeiro: Graal, 2004a.

. Vigiar e punir: nascimento da prisão. Trad. Raquel Ramalhete. Petrópolis: Vozes, 2004b.

A arqueologia do saber. Rio de Janeiro: Forense Universitária, 2005a.

A ordem do discurso. São Paulo: Loyola, 2005b.

HABERMAS, Jürgen. Técnica e Ciência enquanto ideologia. Trad. Zeljko Loparic; Andréa Maria Altino de Campos Loparic. São Paulo: Abril Cultural, 1975. (Coleção Os Pensadores).

. Conhecimento e interesse. Trad. José N. Heck. Rio de Janeiro: Guanabara, 1982.

. Wahrheit und Rechtfertigung? Philosophische Aufsätze. Frankfurt: Suhrkamp, 1984.

. Dialética e Hermenêutica: para a crítica da hermenêutica de Gadamer. Trad. Álvaro L.M. Valls. Porto Alegre: L\&PM, 1987.

Direito e Democracia: entre a facticidade e validade. Trad. Flávio Beno Siebeneichler. Vol. I. Rio de Janeiro: Tempo Brasileiro, 1997.

1993.

Passado como futuro. Trad. Flávio Beno Siebeneichler. Rio de Janeiro: Tempo Brasileiro,

O discurso filosófico da modernidade: doze lições. Trad. Luiz Sérgio Repa; Rodnei Nascimento. São Paulo: Martins Fontes, 2000.

. A inclusão do outro: estudos de teoria política. Trad. George Sperber; Paulo Astor Soethe. São Paulo: Loyola, 2002a.

Pensamento pós-metafísico: estudos filosóficos. Trad. Flávio Beno Siebeneichler. Rio de Janeiro: Tempo Brasileiro, 2002b.

HOYOS, Guillermo; VARGAS, Germán. Teoría de la acción comunicativa como nuevo paradigma de investigación en las ciencias sociales. Bogotá: Icfes, 1997.

HUSSERL, Edmund. A crise da humanidade européia. Trad. Urbano Zilles. Porto Alegre: EDIPUCRS, 2002.

LOHMANN, Georg. Kritische Gesellschaftstheorie ohne Geschichtsphilosophie? Zu Jürgen Habermas' verabschiedeter und uneingestandener Geschichtsphilosophie. In: WELZ, Frank; 
WEISENBACHER, Uwe (Org.). Soziologischee Theorie und Geschichte. Zur Bedeutung der Geschichte für die soziologische Theorie. Wiesbaden/Opladen: Westdeutscher, 1998.

MACHADO, Roberto. Ciência e saber: A trajetória da arqueologia de Michel Foucault. Rio de Janeiro: Graal, 1982.

PIZZI, Jovino. Ética do discurso: a racionalidade ético-comunicativa. Porto Alegre: EDIPUCRS, 1994.

RABINOW, Paul; DREYFUS, Hubert L. Uma trajetória filosófica: para além do estruturalismo e da hermenêutica. Rio de Janeiro: Forense Universitária, 1995.

RICOEUR, Paul. Interpretação e Ideologias. Trad. Hilton Japiassu. Rio de Janeiro: Francisco Alves, 1983.

TERNES, José. A morte do sujeito. In: CASTELO BRANCO, Guilherme; PORTOCARRERO, Vera (Org). Retratos de Foucault. Rio de Janeiro: Nau, 2000.

VEYNE, Paul. Um arqueólogo escéptico. In: DIDIER, Eribon (Org.). E1 infrecuentable Michel Foucault: renovación del pensamiento crítico. Buenos Aires: Letra Viva \& Edelp, 2004. 